\title{
So what? Now what? Exploring, understanding and using the epistemologies that inform the improvement of healthcare
}

\author{
Paul Batalden, ${ }^{1}$ Frank Davidoff, ${ }^{2}$ Martin Marshall, ${ }^{3}$ Jo Bibby, ${ }^{3}$ \\ Colin Pink ${ }^{3}$
}

\section{HOW WE ASSEMBLED THIS SUPPLEMENT}

Our interactions during the Colloquium led to an outpouring of creative and innovative thought about improving healthcare. We re-explored and reframed old ideas, and came up with new ones. The process reminded many of us of the way Native American elders were said to go about reaching decisions: 'Talk and talk until the talk begins." ${ }^{1}$ And importantly, we recognised both explicit and implicit invitations to take action, as we probed the various ways in which people could build on and use such knowledge.

In putting together this supplement, we decided, in general, not to follow the traditional procedure of publishing the inputs: the scripted material participants prepared beforehand, and presented in the initial days of the meeting. Instead, with a few exceptions, it seemed

\section{(0) UNIOCKAD}

This paper is freely available online under the BMJ Journals unlocked scheme, see http://qualitysafety. bmj.com/site/about/unlocked.xhtml

\footnotetext{
${ }^{1}$ The Dartmouth Institute for Health Policy and Clinical Practice, Dartmouth Medical School, Hanover, New Hampshire, USA; ${ }^{2}$ Institute for Healthcare Improvement, Cambridge, Massachusetts, USA; ${ }^{3}$ The Health Foundation, London, UK

Correspondence to Professor Paul Batalden, The Dartmouth Institute for Health Policy and Clinical Practice, Lebanon, NH 03766, USA; paul.batalden@gmail.com
}

closer to the spirit of the meeting to assemble the outputs: the collective explorations, insights and syntheses that emerged from our intense and productive week together. Accordingly, we invited participants, as individuals or in small groups, to write about the ideas from the meeting that changed their thinking the most and that they felt would be important to share. Many chose to do so in a longer ( 2500 -word) format: serious, scholarly, welldocumented articles written to be as accessible as possible to a general readership. Several opted for a shorter ( $\sim 800$-word) format that captured 'ideas in evolution': thinking that seemed too interesting and important to lose, even though it was not yet fully worked out. All of the submitted manuscripts were peer-reviewed.

\section{COLLECTIVE WISDOM THAT EMERGED IN THE COURSE OF THE MEETING}

The resulting papers fell naturally into six structural groups:

1. structure of improvement knowledge;

2. discovering and defining sources of evidence;

3. social determinants of action;

4. importance of cross-disciplinary work;

5. challenges of professional education;

6. rethinking methods of inference.
What follows is a summary of the key elements expressed in the cluster of papers that came together in each group.

1. Structure of improvement knowledge

- Frank Davidoff, in Systems of service: relections on the moral foundations of improvement, contrasts the ways in which 'evangelists and snails' think and work to serve patients better. ${ }^{2}$ Both are motivated by the professional commitment to 'unceasing movement towards new levels of performance,' yet each is convinced that their approach is more acceptable on moral grounds. Both approaches are arguably essential, which presents us with the challenge of combining two orthogonal approaches without losing the identity or unique value of either. He suggests that rapprochement may not only be possible, but may already be under way.

- In a short piece, Davidoff, in Heterogeneity: we can't live with it, and we can't live without it, also notes that, if it is to be useful, knowledge for improvement must accept the value of both 'homogeneity' and 'heterogeneity' in the effects, populations and diseases we work with. ${ }^{3}$ This will require attention to our language, categories, methods and rules of inference.

- Paul Glasziou and colleagues, in Can evidence-based medicine and clinical quality improvement learn from each other?, invite us to recognise that efforts to learn 'the right thing to do' (ie, be informed on evidence-based medicine), and to 'do the right thing' (ie, apply that knowledge reliably in system-level, datadriven quality improvement) are two sides of the same coin in producing the best possible healthcare. ${ }^{4}$ We will need to express their complementarity, and integrate them, at every level: in the care we provide, the 
classes we teach and the assessments of excellence that we make. Unfortunately, this global vision is not yet widely understood; nor is it widely implemented.

- John Øvretveit, in Understanding the conditions for improvement: research to discover which context influences affect improvement success, suggests that studies of improvement interventions might be more useful if the details of the intervention itself, its actual implementation and the context into which it is introduced were described more completely and clearly, including precise accounts of what actions were taken to carry out which changes. ${ }^{5}$ If differences in outcomes were due to the context of the improvement, and if the intervention changed as implementation progressed, what were those differences and those changes?

- Rocco Perla and Gareth Parry, in The epistemology of quality improvement: it's all Greek, observe that since Aristotle we have known that 'How do we really know?' (or 'What is true knowledge'?) is a complex question, the answer to which involves both knowing and believing. Improving the quality, safety and value of healthcare demands careful attention to both dimensions; scientific advancement of the improvement of healthcare will demand unflinching and open consideration of 'how we know.' 6

- Laura Leviton, in Reconciling complexity and classification in quality improvement research, reminds us that pioneering naturalists such as Darwin have long recognised the value of disaggregating and engaging in deeper exploration of the "parts." 7 The care of patients and its improvement invite attention to the 'wholes' which are formed by the synthesis and integration of the (often) better understood 'parts.' She describes the potential power of a yet-to-bedeveloped taxonomy for the elements or 'parts' of improvement interventions, their outcomes and their contexts. Development of that taxonomy might progress by collecting and describing exemplars, identifying essential elements for classification, pattern matching and never-ending reflective rematching in practice.

2. Discovering and defining sources of evidence.

- Ross Baker, in The contribution of case study research to knowledge of how to improve quality of care, argues that case studies can, and often do, offer unique insights into the novel aspects of phenomena central to the improvement of healthcare: the adoption of innovation, boundaries between professional groups and team learning processes, for example. ${ }^{8}$ Such studies use both qualitative and quantitative data about improvement in context; they can inform the development of more robust theory that links problem, intervention and outcome. He notes further that case studies are particularly important in understanding why or how things work in real life, rather than in theory. They are, however, methodologically demanding and require particularly careful collection and analysis of data from diverse sources.

- Duncan Neuhauser and colleagues, in The meaning of variation to healthcare managers, clinical and health-services researchers, and individual patients, note that the classical work by Shewhart, Deming and others focused sharply on exploring and understanding unwanted variation as a key to redesigning a healthcare system with the highest possible quality, safety and value. ${ }^{9}$ They observe that managers, researchers and patients/care givers are each trying to answer different questions as they work with unwanted variation. They describe and illustrate some of the methods available for each group as they struggle with the problem of variation.

- Bo Bergman and colleagues, in Five main processes in healthcare; a citizen perspective, offer a 'citizen's eye' framework of healthcare at the macro level. ${ }^{10}$ Seeing things from this perspective invites attention to the relation between disease and the lived experience of illness and its prevention; between the process of delivering care and receiving it. Meaningful improvement is improved by having different 'eyes' view the processes involved.

3. Social determinants of action

- Ann Langley and Jean-Louis Denis, in Beyond evidence: the micropolitics of improvement, suggest that specific improvement efforts will usually fail unless they take into account the pattern of interests, values and power relationships that surround them. ${ }^{11}$ The inescapable conclusion here is that successful implementation of improvement programmes requires an understanding of organisations as political systems, and management of the relationships, particularly the power relationships, that are involved. The authors' extensive experience in observing improvement in action has allowed them to (1) recognise the distribution of costs and benefits among patients, providers, organisations and society; (2) see a variety of value systems and interests at work; and (3) appreciate that most changes for improvement have both a hard scientific core and a soft, context-specific and largely social periphery.

- Mary Dixon-Woods and colleagues, in Problems and 
promises of innovation: why healthcare needs to rethink its love/hate relationship with the new, note that the evaluation of innovation is often too narrowly focused to understand the system-wide effects of new practices or technologies. ${ }^{12}$ They describe three paradoxes of 'the new' that are often present and which illustrate the situation: (1) the all-toocommon uptake of the dubious, and rejection of the good; (2) the wisdom and failings of democracy as the remedy for such misplaced judgements; (3) the law of unanticipated consequences: improvement requires change, but change always generates more challenges. Recognising that a different approach may be needed, these authors consider asking different questions: (a) What is the evidence the (intervention) can and does improve outcomes in other settings, recognising that the art and science of generalisation are inherently difficult? (b) What training and support systems will be needed before an improvement intervention is introduced, in order for it to realise its full potential? and (c) How should we monitor the introduction of that intervention? In short, they invite us to look before, after, up, down and to the sides, with each innovation.

- Joanne Lynn and colleagues, in Clarity and strength of implications for practice in medical journal articles: an exploratory analysis, empirically examined two literatures for practitioners-clinical and management-and found two different norms for recommending action. ${ }^{13}$ The majority of original articles from three leading healthcare clinical journals $(68.6 \%)$ simply stated that one intervention was (or was not) different from another in its effects.
Reports in these journals directed a particular action ('therefore, $\mathrm{x}$ should be done') only $25.5 \%$ of the time. Only one article gave further instruction on how to implement the changes. Twothirds of the reports called for further research. Half used tentative language. In contrast, original reports in management journals nearly always specified who should use the information, drawing from over 60 types of potential users, whereas only $23.5 \%$ of reports in the clinical journals explicitly named the targeted agent, and then overwhelmingly targeted only physicians or clinicians. They conclude that authors and editors of the clinical literature should consider testing clearer, more direct and more consistent ways to present the implications of research findings for practice, perhaps using as models the structured methods employed in certain clinical guidelines.

- Joanne Lynn, in Building an integrated methodology of learning that can optimally support improvements in healthcare, suggests that we lack methods for building the knowledge we need to guide true healthcare reform. ${ }^{14}$ She argues that we assume we can use the sources and methods that, in the past, have helped us build the enormous body of evidence for the efficacy and safety of clinical tests, drugs and procedures. Unfortunately, those sources and methods do not 'take us all the way' to reform; from her example of decreasing falls in older people, it is easy to see their limits. Our conventional methods of accumulating evidence can help us understand which medications are likely to have which effects, but they cannot help us choose the optimal combination of individual patients, and the settings in which they live, with tools for clinical management. She notes further that there is an almost unending set of 'comment points' between health policy and the improvement of care, and challenges us to find the voice to make those comments.

4. Importance of cross-disciplinary work

- Jean Bartunek, in Intergroup relationships and quality improvement in healthcare, calls our attention to intergroup dynamics, such as those that are associated with social identity, enable communities of practice and contribute to the formation of professional identity. ${ }^{15}$ These factors all allow healthcare professionals to gain a sense of mastery and joy in work, but at the same time can be important sources of isolation, friction and inefficiency. She suggests that fostering dual identities for workers prepared in different professions can contribute to better intergroup relationships, as can fostering communities of practice, and making explicit the positive examples of crossprofessional groups as part of the professional socialisation process.

- Molly Cooke, in Expert patientslearning from $H I V$, describes her own journey of moving from a mindset of 'patients versus providers' to one of 'patients and providers versus the burden of illness. ${ }^{16}$ She notes that this transition can free up enormous energy and can generate deep satisfaction for both patient and provider.

- Don Goldmann, in Ten tips for incorporating scientific quality improvement into everyday work, provides a 'nuts and bolts' guide to incorporating solid, carefully planned improvement initiatives into daily clinical work. ${ }^{17}$ Drawing colleagues from a wide spectrum of disciplines into the work of 
developing and testing explicit operating principles such as these can make it easier to study, maintain, extend, replicate and report improvements achieved.

- Charles Vincent and colleagues, in Multidisciplinary centres for safety and quality improvement: learning from climate change science, suggest that bringing together representatives of diverse professional disciplines geographically, intellectually and socially is likely to create important and entirely new ways of improving the quality, safety and value of healthcare. ${ }^{18}$ But achieving robust, effective cross-disciplinary groups is a demanding task. It will require the development of contexts that drive towards practical goals, enjoy stable financial support, attract thoughtful people from traditional settings and career pathways, and sustain them in a new and seemingly alien environment. A model that illustrates the value of this approach may be found in centres that have coalesced around the issue of climate change.

5. Challenges of professional education

- Molly Cooke and colleagues, in Mainstreaming quality and safety: a reformulation of quality and safety education for health professions students, note several developments that will be necessary to bring learning about healthcare improvement into the mainstream of health professions education. ${ }^{19}$ First, improvement must be seen as part of all clinical encounters. Second, students and their teachers must become colearners as they collaborate to improve the care they are giving and learning about. Third, improved quality and safety must be seen as arising from interdependent work among professionals rather than the knowledge and skills of individual practitioners. Fourth, outcome assessments must focus less on what individual learners know and can do, and more on how care teams' patients fared, and how well system improvements actually worked. Items 3 and 4 in particular offer the opportunity to explore the promises that underpin interdependent work: promises to patients about the performance of the care system, its outputs and the roles of individual providers within that system; and promises to coworkers about reliable performance of one's own work in relation to that of others.

- Rick Iedema, in Creating safety by strengthening clinicians' capacity for reflexivity, observes that realtime care giving is a complex event in which providers interested in better safety must reflect and reflexively act. ${ }^{20} \mathrm{He}$ points out that in situ videography makes it possible to learn and reflect on the work and on the reflexive actions that are embedded in these real situations of healthcare. This process can enable practitioners to question their own habits in a way that can impact on who they are and how they relate.

6. Rethinking methods of inference

- John Øvretveit and colleagues, in Increasing the generalisability of improvement research with an improvement replication programme, suggest that purposeful, studied replication of improvement programmes is the most direct way to increase the generalisability of improvement strategies, albeit a demanding task. ${ }^{21}$ Meaningful replication requires careful description of the context as well as the intervention, noting the adaptations made as the intervention unfolds, and as repeated tests of the same intervention are carried out in different and diverse settings.
- Lloyd Provost, in Analytic studies: a framework for quality improvement design and analysis, challenges us to recognise that traditional statistical inference, as found in 'enumerative' studies, makes possible actions that are applicable only to the system that was studied, and as it was when it was studied; the time dimension is essentially lacking in such inference. ${ }^{22}$ The results of 'analytical' studies, in contrast, apply to actions on systems under the changed conditions in which they exist at future times. Since change over time is essentially the defining characteristic of improvement, the design, execution, evaluation and reporting of improvement thus require an analytical approach. We are really just beginning to understand the profound implications of this reasoning, and profit from those insights.

- Steven Goodman, in Confessions of a chagrined trialist, observes that 'everything' changes when an intervention is intended to affect individual or group performance, rather than patient biology. ${ }^{23}$ He notes that we live and build knowledge in our own cognitive and experiential frames. Fostering meaningful cross-frame experiences can permit the increased mental agility; reflection on personal experiences, stories and responses can open curiosity and change the questions asked.

\section{A SYNTHESIS}

The human reality of healthcare is easy to lose in the proliferating jungle of inanimate technical wonders that are looked to increasingly as the way we will 'really' get better healthcare. But the wisdom captured in the discussions at Cliveden suggests that we will continue to be deeply disappointed if we expect biological 
wizardry and technical fixes, for all their power and value, to do the job by themselves.

More importantly, this wisdom asserts that because healthcare is, at its core, a giving and receiving by sentient human beings, as individuals and in social groups, the real power for improvement will therefore lie in mastering the complex realities that drive, and that inhibit, human performance, professional behaviour and social change. For example: the expression of individual and group self-interest; the ways that people assert power and control; the strength of group identity and communities of practice; the mysteries of context and its influence; the moral assumptions that underlie methods of evaluation; the importance of belief, as well as understanding, in knowledge; the strengths and limitations of 'group-think,' also known as, democracy, the enormous and mostly untapped power of cooperative, crossdisciplinary learning and action are all illustrative. In short, we need to modulate our magical thinking about the value of tools and techniques by seriously entering into the 'alternate universe' of Aristotelian phronesisbecoming capable of action with regard to the things that are good for humankind. ${ }^{24}$

It seems unlikely that we can distil a single overarching principle from the wealth of thought that came out of the meeting at Cliveden, and it might even be counterproductive to try. But if we were to make the effort, the result might look something like this: 'Even at its most scientific and technical moments, the provision of healthcare is always - always - a social act.'

So much more seems possible as traditional boundaries of thinking are extended, as context assumes its legitimate place of importance, as we explicitly recognise the benefits of psychology, sociology and other disciplines, and integrate those disciplines better into our ways of caring and learning as health professionals.

So many possible actions emergefor example: revise the curricula of health professional education; lobby research publishers and funders; develop and appoint leaders capable of using these 'sciences of improvement'; and so many more.

How can we best ground, develop and nourish the vitality of these efforts at building and applying knowledge, while simultaneously obtaining the leverage needed for this much change?

Though developed outside this Colloquium, Shneiderman described collaboration-centred socio-technical systems that were needed to study the integrated interdisciplinary problems in the real world. He called them 'collaboratories. ${ }^{25}$ A 'collaboratory' around the scholarship and science of improvement for graduate study in a variety of relevant disciplines seemed timely as one important way to explore the formal advancement of the science of improvement in the 'real world.'

\section{A PROPOSAL FOR ACTION: A NEW TRAINING PROGRAMIME BASED ON THE MULTIPLE EPISTEMOLOGIES INFORMING HEALTHCARE IMPROVEMENT}

Over the years, the application of biomedical science has illustrated the benefits of having not only expert clinical practitioners but also scholarly leaders from other disciplines committed to pushing back the boundaries of knowledge. The improvement world has yet to realise this benefit at scale. Improvement is still regarded by some as the domain of the enthusiasts, evangelists even; light on theory, and even lighter on hard, peer-reviewed evidence. But improvement can and should be rigorous and systematic, and, as illustrated by the series of articles in this supplement, it does have its own growing body of empirical evidence to guide practice. What it does not yet have is an adequate number of academic leaders, theoreticians and empiricists, driven by a spirit of enquiry, who can extend our understanding of what works where and why - the intellectual tools we need to improve patient care. This is not the kind of science practised in darkened rooms or in pristine laboratories. It is a highly applied science; it deals with the complex, messy problems in the 'swamps' of the real world, rather than the well-formulated hypotheses of the academic world. The tools at its disposal are equally complex. Its development requires scientists to have a deep understanding of the environment within which their work is applied and an intimate relationship with both the practitioners and those who use the service.

In many countries, we will discover handfuls of such people, most of them self-trained, who have found their way into the improvement world more by accident than by design. If improvement science is to flourish, we argue that the next generation of improvement science leaders will need to be developed in a more purposeful way. The Health Foundation, an independent charity based in London, England, is rising to this challenge. In late 2010, it launched a new training scheme which aims to produce the future leaders of improvement science in the UK. Our vision is that these individuals will, within $5-10$ years, be leading many of the developing partnerships between higher-education institutes and health services; they will be bringing together academics, clinicians and managers from across sectors and disciplines in a common endeavour to develop the knowledge base that underpins improvement.

To ensure the quickest and safest return on investment, this scheme will in the first instance be aimed at 
postdoctoral scientists and scholars. Applicants will need a track record of high-quality, applied research in the field of quality of care and formal training in any discipline that makes a useful contribution to the science of improvement. Given the applied nature of improvement science, it is likely that many, but not all, will have experience of providing service in either a clinical or managerial role. The duration of the fellowship will be at least 3 years, and it will comprise not only a programme of research, but also opportunities to become expert in all aspects of improvement science, and develop the highest calibre of leadership and influencing skills.

Successful applicants will be hosted by academic institutions with a track record of support for postdoctoral students, a reputation as a leader in the field of quality of care and improvement research, and effective existing partnerships with local healthcare services. All of the host institutions will work closely together to ensure a sustainable learning environment that benefits the training fellows collectively as well as individually. The Health Foundation is committed to supporting learning across national boundaries, and to this end has established an international network of leading experts in the field of improvement science. In addition to local supervision and mentorship from the host institution, the fellows in this new programme will have access to this network of experts, and will build international collaborations to help develop the knowledge base of improvement.

If the scheme is successful, we will see within the next decade a growing and highly influential cohort of leaders of improvement science in the UK. In parallel, the Health Foundation would like to see similar schemes in other countries that are operating on a similar model, accessing the international network and contributing to a collective global endeavour to strengthen improvement science in their health sectors. No one among us underestimates how difficult it will be to attract the brightest of talents to a new specialty, encourage a genuine shared understanding between disparate academic disciplines and successfully align the array of incentives in the academic and health sectors. The challenges are great, but potential benefits even greater.

\section{CONCLUSION}

We submit that it is knowledge-both knowing what and knowing how, episteme and techne; knowledge that we will continue to seek, build, share, use, assess, recognise and rewardthat enables (and constrains) what we can do to improve the quality, safety and value of healthcare. Further, it is our belief that the work done in preparation for, during and following this meeting is only the beginning of unending and everexpanding future work towards that knowledge. We hope this invites others to the journey we have shared so far.

\section{Acknowledgements The members of this} Colloquium were: $\mathrm{R}$ Amalberti, $\mathrm{MD}, \mathrm{PhD}$, Professor and Senior Advisor on Patient Safety, Haute Autorité de Santé, Paris, France; GR Baker, $\mathrm{PhD}$, Professor, Department of Health Policy, Management and Evaluation, University of Toronto, Toronto, Canada; J Bartunek, PhD, Professor of Organization Studies, Boston College, Boston, Massachusetts, USA; P Batalden, MD, Professor \& Director, Center for Leadership and Improvement, The Dartmouth Institute for Health Policy and Clinical Practice, Dartmouth Medical School, Hanover, New Hampshire, USA; P Bate, PhD, Professor Emeritus, The Medical School, University College, London, UK;

B Bergman, PhD, Professor, Chalmers University of Technology, Gothenburg, Sweden; J Bibby, $\mathrm{PhD}$, Director of Improvement Programmes, The Health Foundation, London, UK; M Cooke, MD, Professor of Medicine, University of California, San Francisco, California, USA; F Davidoff, MD, Executive Editor, Institute for Healthcare Improvement, Cambridge, Massachusetts, USA; M Dixon-Woods, PhD, Professor of Sociology, University of Leicester, Leicester, UK; P Glasziou, $\mathrm{MD}, \mathrm{PhD}$, Director, Centre for Evidence-Based Medicine, University of Oxford, Oxford, UK;
D Goldmann, MD, Senior Vice President, Institute for Healthcare Improvement, Professor, Harvard Medical School and School of Public Health, Cambridge, Massachusetts, USA; S Goodman, $\mathrm{MD}, \mathrm{PhD}$, Professor of Oncology, Pediatrics, Biostatistics, \& Epidemiology, Johns Hopkins Schools of Medicine and Public Health, Baltimore, Maryland, USA; P Hawe, PhD, Professor and Markin Chair in Health and Society, Population Health Intervention Research Centre, University of Calgary, Alberta, Canada; R ledema, PhD, Professor and Director, Centre for Health Communication, University of Technology, Sydney, Australia; P Ironside, RN, PhD, Associate Professor and Director, Center for Nursing Education Research, Indiana University, Indianapolis, Indiana, USA; A Langley, PhD, Professor of Strategic Management, HEC Montréal, Montréal, Canada; L Leviton, PhD, Special Advisor for Evaluation, The Robert Wood Johnson Foundation, Princeton, New Jersey, USA; J Lynn, MD, MA, MS, Bureau Chief, Department of Health, Washington, District of Columbia, USA; M Marshall, MD, PhD, Clinical Director and Director, Research and Development, The Health Foundation, London, UK; D Neuhauser, PhD, Professor of Health Management, Department of Epidemiology and Biostatistics Medical School, Case Western Reserve University, Cleveland, Ohio, USA; G Ogrinc, MD, Associate Professor, Director, Office of Research and Innovation in Medical Education, Dartmouth Medical School, Hanover, New Hampshire, USA; J Øvretveit, PhD, Professor of Health Innovation Implementation and Evaluation, Director of Research, Medical Management Centre, The Karolinska Institute, Stockholm, Sweden; G Parry, PhD, Research Scientist, Institute for Healthcare Improvement, Boston, Massachusetts, USA; L Provost, Improvement Advisor, Associates in Process Improvement, Austin, Texas, USA; D Stevens, $M D$, Editor-in-Chief, Quality and Safety in Health Care, Adjunct Professor and Director, Quality Literature Program, The Dartmouth Institute for Health Policy and Clinical Practice, Hanover, New Hampshire, USA; S Thornton, Chief Executive, The Health Foundation, London, UK; C Vincent, $\mathrm{PhD}$, Professor of Clinical Safety Research, Department of Surgical Oncology and Technology, Imperial College, London, UK; $\mathrm{D}$ Webb, PhD, Director of Evaluation and Strategy, The Health Foundation, London, UK.

Competing interests None.

Provenance and peer review Not commissioned; not externally peer reviewed.

BMJ Qual Saf 2011;20:i99-i105.

doi:10.1136/bmjqs.2011.051698

\section{REFERENCES}

1. Senge P. Forward in Isaacs W. Dialogue and the Art of Thinking Together. New York: Doubleday, 1999:xvii.

2. Davidoff F. Systems of service: the moral foundations of clinical research and improvement science. BMJ Qual Saf 2011;20(S1):i5-i10.

3. Davidoff F. Heterogeneity: we can't live with it, and we can't live without it. BMJ Qual Saf 2011;20(S1):i11-i12. 
4. Glasziou PP, Ogrinc G, Goodman S. Can evidence-based medicine and clinical quality improvement learn from each other? BMJ Qual Saf 2011;20(S1):i13-i17.

5. Øvretveit J. Understanding the conditions for improvement: research to discover which context influences affect improvement success. BMJ Qual Saf 2011;20(S1):i18-i23.

6. Perla R, Parry GJ. The epistemology of quality improvement: it's all Greek. BMJ Qual Saf 2011;20(S1):i24-i27.

7. Leviton LC. Reconciling complexity and classification in quality improvement research. BMJ Qual Saf 2011;20(S1):i28-i29.

8. Baker GR. The contribution of case study research to knowledge of how to improve quality of care. BMJ Qual Saf 2011;20(S1): i30-i35.

9. Neuhauser DB, Provost LP, Bergman B. The meaning of variation to healthcare managers, clinical and health-services researchers, and individual patients. BMJ Qual Saf 2011;20(S1):i36-i40.

10. Bergman B, Neuhauser DB, Provost LP. Five main processes in healthcare: a citizen perspective. BMJ Qual Saf 2011;20(S1): i41-i42.
11. Langley A, Denis JL. Beyond evidence: the micropolitics of improvement. BMJ Qual Saf 2011;20(S1):i43-i46.

12. Dixon-Woods M, Amalberti R, Goodman S, et al. Problems and promises of innovation: why healthcare needs to rethink its love/ hate relationship with the new. BMJ Qual Saf 2011;20(S1):i47-i51.

13. Lynn J, Owens AP, Bartunek J. Clarity and strength of implications for practice in medical journal articles: an exploratory analysis. BMJ Qual Saf 2011;20(S1):i52-i57.

14. Lynn J. Building an integrated methodology of learning that can optimally support improvements in healthcare. BMJ Qual Saf 2011;20(S1):i58-i61.

15. Bartunek JM. Intergroup relationships and quality improvement in healthcare. $B M J$ Qual Saf 2011;20(S1):i62-i66.

16. Cooke M. Expert patients-learning from HIV. BMJ Qual Saf 2011;20(S1):i67-i68.

17. Goldmann D. Ten tips for incorporating scientific quality improvement into everyday work. BMJ Qual Saf 2011;20(S1): i69-i72.

18. Vincent C, Davidoff F, Batalden P. Multidisciplinary centres for safety and quality improvement: learning from climate change science. BMJ Qual Saf 2011;20 (S1):i73-i78

19. Cooke M, Ironside PM, Ogrinc GS Mainstreaming quality and safety: a reformulation of quality and safety education for health professions students. BMJ Qual Saf 2011;20(S1):i79-i82.

20. ledema R. Creating safety by strengthening clinicians' capacity for reflexivity. BMJ Qual Saf 2011;20(S1):i83-i86.

21. Øvretveit J, Leviton L, Parry G. Increasing the generalisability of improvement research with an improvement replication programme. BMJ Qual Saf 2011;20(S1): i87-i91.

22. Provost LP. Analytic studies: a framework for quality improvement design and analysis. BMJ Qual Saf 2011;20(S1): i92-i96.

23. Goodman S. Confessions of a chagrined trialist. BMJ Qual Saf 2011;20(S1): i97-i98.

24. Flyvbjerg B. Making Social Science Matter Cambridge: Cambridge University Press, 2001

25. Shneiderman B. Science 2.0. Science 2008;319:1349-50. 